\title{
Negative lymph node count is an independent prognostic factor for patients with rectal cancer who received preoperative radiotherapy
}

\author{
Xinxing $\mathrm{Li}^{1 \dagger}$, Hao Lu ${ }^{1 \dagger}$, Kai Xu${ }^{1}$, Haolu Wang ${ }^{2}$, Xiaowen Liang ${ }^{2^{*}}$ and Zhiqian $\mathrm{Hu}^{1 *}$
}

\begin{abstract}
Background: Negative lymph node (NLN) count has been reported to provide more accurate prognostic information than the $\mathrm{N}$ stage alone in patients with rectal cancer (RC). Since preoperative radiotherapy (Pre-RT) can significantly affect the LN status, it is unclear whether NLN count still has prognostic value count on survival of patients with RC who received Pre-RT.

Methods: In this study, clinicopathological characteristics, number of positive LNs and survival time were collected from Surveillance, Epidemiology, and End Results Program (SEER)-registered RC patients. Univariate and multivariate Cox proportional hazards models were used to assess the risk factors for survival.

Results: X-tile plots identified $9(P<0.001)$ as the optimal cutoff NLN value to divide the patients into high and low risk subsets in terms of cause specific survival (CSS). NLN count was validated as independently prognostic factor in univariate and multivariate analysis $(P<0.001)$. Subgroup analysis showed that NLN count was an independently prognostic factor for patients with stage ypll $(P=0.002)$ and ypllI $(P<0.001)$.

Conclusions: Our results firmly demonstrated that NLN count provides accurate prognostic information for RC patients with Pre-RT.
\end{abstract}

Keywords: Rectal cancer, Preoperative radiotherapy, Negative lymph node, Survival

\section{Background}

Rectal cancer (RC) is one of the most common malignancies in the USA, and the incidence of RC in Asian countries is increasing rapidly and has been considered to be similar to that of the Western countries [1]. Preoperative radiotherapy (Pre-RT) has become part of standard practice offered to improve treatment outcomes in patients with RC because of the oncologic benefit of reduced local recurrence rate [2]. But till now, there is still lack of effective means for accurate prognostic evaluation on the survival.

\footnotetext{
* Correspondence: x.liang@uq.edu.au; huzhiq163@163.com

${ }^{\dagger}$ Equal contributors

${ }^{2}$ Therapeutics Research Centre, School of Medicine, The University of Queensland, Princess Alexandra Hospital, Woolloongabba, QLD 4102, Australia

'Department of General Surgery, Changzheng Hospital, The Second Military Medical University, 415 S. Fengyang Road, Shanghai 200003, China
}

It is widely thought that lymph node (LN) metastasis indicates worse tumor response grade and poorer survival. According to the guidelines for RC from the National Comprehensive Cancer Network, a minimum of twelve lymph nodes must be retrieved and examined for accurate staging and the number of metastatic LNs was validated as an independent prognostic factors [3]. While the node-positive patients with RC are heterogeneous and the prognosis of these patients cannot be stratified by the node-stage only [3, 4]. Therefore, the concept of negative lymph node (NLN) counts has attracted attention recently as a prognostic indicator in various cancers, including breast [5], cervical [6], and esophagus [7]. It has been reported that the number of NLNs was an independent prognostic factor for patients with colon cancer [8]. However, Pre-RT can yield tumor downstaging, reduce the 
burden of residual microscopic disease at surgery and reduce the number of LNs retrieved in operation [9]. With the decreased LNs retrieval, the prognostic value of the LN count might also diminish [10]. It has been reported that increased number of NLNs is associated with improved survival in pathological IIIB and IIIC RC treated with Pre-RT [7]. While it is still unclear whether NLN still has prognostic value count on survival of all patients with RC, including stage I and II, who received Pre-RT. The purpose of this study was to assess the association between NLN count and survival of patients with $\mathrm{RC}$ of all stages who received Pre-RT. In order to get convincing results in a larger series patients, we used the SEER (Surveillance, Epidemiology and End Results)-registered database to analyze this association, and determine the optimal cutoff value of NLN count.

\section{Methods}

\section{Study population and data extracted}

The SEER (Surveillance, Epidemiology, and End Results Program) database and SEER-stat software
(SEER Stat 8.3.2) were used to identify patients whose pathological diagnosis as RC between 2004 and 2010. Only patients who underwent Pre-RT and surgical treatment with age of diagnosis more than 18 years were included. Histological type were limited to adenocarcinoma (8140/3), carcinoma $(8010 / 3 ; 8020 / 3$; $8021 / 3$ and $8145 / 3$ ) and signet ring cell carcinoma $(8490 / 3)$. Patients were excluded if they had only local excision following Pre-RT, multiple primary malignant neoplasms, incomplete TNM staging, with distant metastasis (M1), no evaluation on LNs, died within 30 days after surgery or information on CSS and survival months unavailable.

Year of diagnosis, age, sex, race, grade, histologic type, ypT stage, number of LNs examined, number of positive LNs and CSS were assessed. TNM classification was restaged according to the criteria described in the AJCC Cancer Staging Manual (7th edition, 2010).

\section{Statistical analysis}

The NLNs cutoff points were determined using the X-tile program, which identified the cutoff value

Table 1 Univariate analysis of the influence of different NLN count on CSS in RC patients who received Pre-RT

\begin{tabular}{|c|c|c|c|c|c|c|c|c|c|}
\hline LNs & No. & 5-year CCS & $x^{2}$ & $P$ value & LNs & No. & 5-year CCS & $x^{2}$ & $P$ value \\
\hline$\leq 0$ & 72 & $51.8 \%$ & 41.745 & 0.000 & $\leq 12$ & 3685 & $76.5 \%$ & 42.763 & 0.000 \\
\hline$>0$ & 5996 & $79.5 \%$ & & & $>12$ & 2383 & $83.3 \%$ & & \\
\hline$\leq 1$ & 230 & $63.5 \%$ & 50.100 & 0.000 & $\leq 13$ & 4022 & $76.9 \%$ & 38.747 & 0.000 \\
\hline$>1$ & 5838 & $79.7 \%$ & & & $>13$ & 2046 & $83.6 \%$ & & \\
\hline$\leq 2$ & 444 & $68.2 \%$ & 44.132 & 0.000 & $\leq 14$ & 4320 & $77.3 \%$ & 33.939 & 0.000 \\
\hline$>2$ & 5624 & $80.0 \%$ & & & $>14$ & 1748 & $83.7 \%$ & & \\
\hline$\leq 3$ & 720 & $69.0 \%$ & 54.496 & 0.000 & $\leq 15$ & 4585 & $77.3 \%$ & 36.435 & 0.000 \\
\hline$>3$ & 5348 & $80.5 \%$ & & & $>15$ & 1483 & $84.8 \%$ & & \\
\hline$\leq 4$ & 1015 & $70.0 \%$ & 67.375 & 0.000 & $\leq 16$ & 4822 & $77.6 \%$ & 33.037 & 0.000 \\
\hline$>4$ & 5053 & $81.0 \%$ & & & $>16$ & 1246 & $85.3 \%$ & & \\
\hline$\leq 5$ & 1314 & $71.8 \%$ & 68.432 & 0.000 & $\leq 17$ & 5013 & $72.8 \%$ & 27.827 & 0.000 \\
\hline$>5$ & 4754 & $81.2 \%$ & & & $>17$ & 1055 & $85.4 \%$ & & \\
\hline$\leq 6$ & 1625 & $72.5 \%$ & 74.979 & 0.000 & $\leq 18$ & 5177 & $78.0 \%$ & 23.546 & 0.000 \\
\hline$>6$ & 4443 & $81.6 \%$ & & & $>18$ & 891 & $85.5 \%$ & & \\
\hline$\leq 7$ & 1974 & $73.5 \%$ & 74.302 & 0.000 & $\leq 19$ & 5302 & $78.0 \%$ & 25.448 & 0.000 \\
\hline$>7$ & 4094 & $81.9 \%$ & & & $>19$ & 766 & $86.8 \%$ & & \\
\hline$\leq 8$ & 2285 & $74.2 \%$ & 70.405 & 0.000 & $\leq 20$ & 5422 & $78.2 \%$ & 25.257 & 0.000 \\
\hline$>8$ & 3783 & $82.1 \%$ & & & $>20$ & 646 & $87.2 \%$ & & \\
\hline$\leq 9$ & 2613 & $74.3 \%$ & 78.060 & 0.000 & $\leq 21$ & 5528 & $77.9 \%$ & 21.120 & 0.000 \\
\hline$>9$ & 3455 & $82.8 \%$ & & & $>21$ & 540 & $87.5 \%$ & & \\
\hline$\leq 10$ & 2973 & $75.0 \%$ & 67.236 & 0.000 & $\leq 22$ & 5606 & $78.4 \%$ & 21.730 & 0.000 \\
\hline$>10$ & 3095 & $83.1 \%$ & & & $>22$ & 462 & $88.0 \%$ & & \\
\hline$\leq 11$ & 3320 & $75.6 \%$ & 57.663 & 0.000 & $\leq 23$ & 5671 & $78.5 \%$ & 18.872 & 0.000 \\
\hline$>11$ & 2748 & $83.4 \%$ & & & $>23$ & 397 & $88.8 \%$ & & \\
\hline
\end{tabular}





Fig. 1 X-tile analysis of survival data from the SEER registry. X-tile analysis was performed using patient data, equally divided into training and validation sets, from the SEER registry. In X-tile plots of the training sets (a), the plots of matched validation sets are shown in the smaller inset. The optimal cut-point highlighted by the black circle (a) is shown on a histogram of the entire cohort (b), and a Kaplan-Meier plot (c). $P$ values were determined using the cutoff point defined in the training set and applying it to the validation set. (The optimal cutoff value for NLN count is $9, \times 2=78.060, P<0.001)$

Table 2 Comparison of clinical characteristics of patients with NLN $\leq 9$ or NLN $>9$

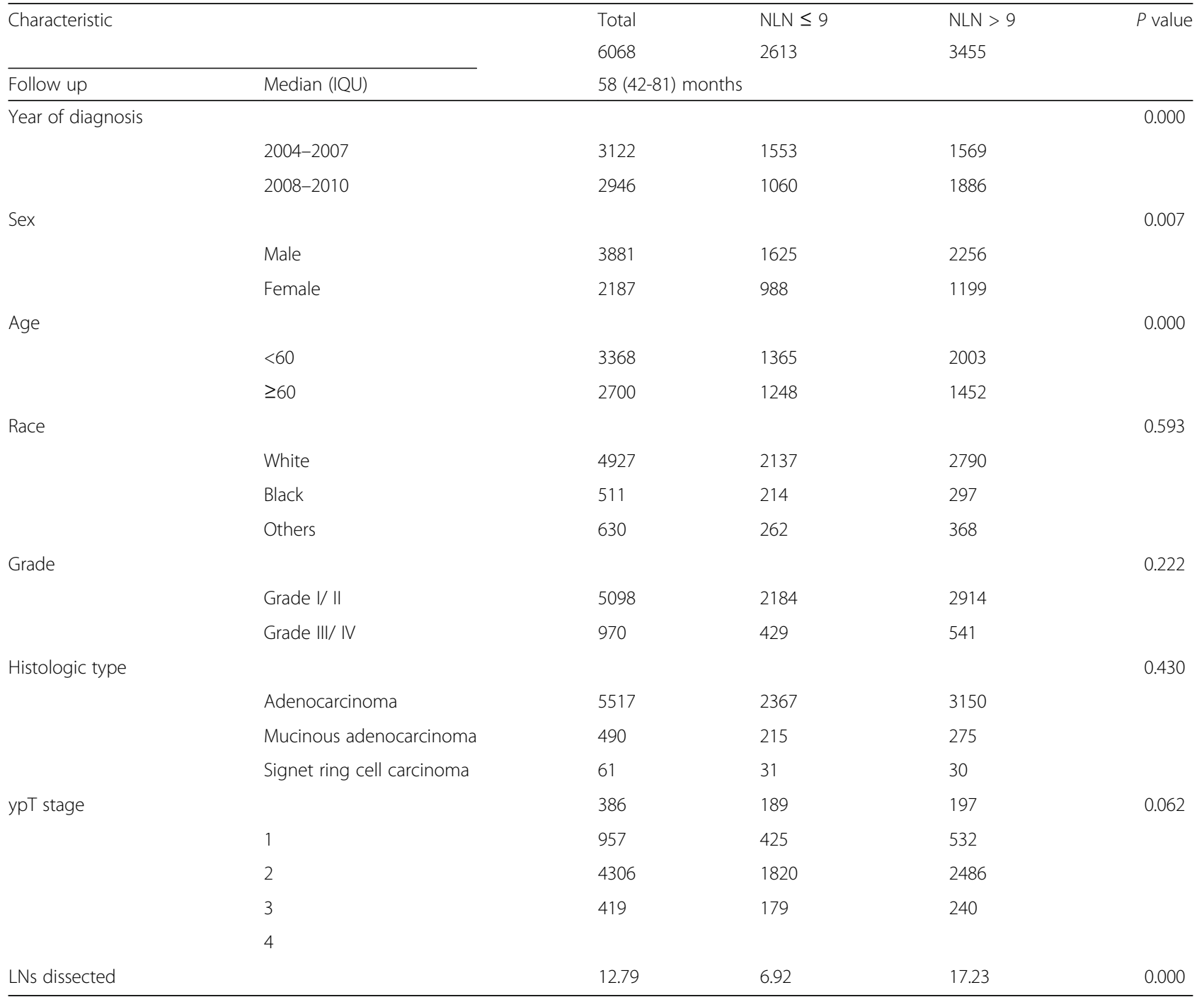


with the minimum $P$ values from log-rank $\chi 2$ statistics for the categorical NLNs in terms of CSS. Baseline characteristics were compared using the X2 test for nominal variables. Survival curves were generated using Kaplan-Meier analyses, and the differences between the curves were analyzed by log-rank test. Cox regression models were built for analysis of risk factors for survival outcomes. Statistical analyses were performed using the statistical software package SPSS for Windows, version 19.0 (SPSS Inc., Chicago, IL). All $P$ values were two-sided. $P<0.05$ was considered statistically significant.

\section{Results}

Patient characteristics from SEER database

In SEER database, we selected a total of 6068 patients with RC who received Pre-RT, including 3881 male and 2187 female from 2004 to 2010 . The median age of patients was 59 years. There were 4042 patients with stage ypN0, 1352 with stage ypN1 and 674 with stage ypN2.

\section{The optimal cutoff value for NLN count calculated by} X-tile

To assess the influence of different NLN count on CSS, we analyzed the individual result using different

Table 3 Univariate and multivariate survival analyses of RC patients who received Pre-RT

\begin{tabular}{|c|c|c|c|c|c|}
\hline \multirow[t]{2}{*}{ Characteristic } & \multirow[t]{2}{*}{ 5-year CCS } & \multicolumn{2}{|c|}{ Univariate analysis } & \multicolumn{2}{|l|}{ Multivariate analysis } \\
\hline & & $x^{2}$ test & $P$ & $\mathrm{HR}(95 \% \mathrm{Cl})$ & $P$ \\
\hline Year of diagnosis & & 2.412 & 0.120 & $\mathrm{NI}$ & \\
\hline 2004-2007 & $78.4 \%$ & & & & \\
\hline 2008-2010 & $80.2 \%$ & & & & \\
\hline Sex & & 1.655 & 0.198 & $\mathrm{Nl}$ & \\
\hline Male & $29.5 \%$ & & & & \\
\hline Female & $78.4 \%$ & & & & \\
\hline Age & & 21.805 & 0.000 & & 0.000 \\
\hline$<60$ & $81.3 \%$ & & & Ref & \\
\hline$\geq 60$ & $76.4 \%$ & & & $0.777(0.697 \sim 0.866)$ & 0.000 \\
\hline Race & & 14.873 & 0.000 & & 0.909 \\
\hline White & $79.5 \%$ & & & Ref & \\
\hline Black & $72.7 \%$ & & & $1.129(0.937 \sim 1.364)$ & 0.202 \\
\hline Others & $81.8 \%$ & & & $1.585(1.246 \sim 2.017)$ & 0.000 \\
\hline Grade & & 112.363 & 0.000 & & 0.000 \\
\hline Grade I/ II & $81.5 \%$ & & & Ref & \\
\hline Grade III/ IV & $66.9 \%$ & & & $0.596(0.523 \sim 0.680)$ & 0.000 \\
\hline Histologic type & & 81.128 & 0.000 & & 0.000 \\
\hline Adenocarcinoma & $80.4 \%$ & & & Ref & \\
\hline Mucinous adenocarcinoma & $69.2 \%$ & & & $0.412(0.308 \sim 0.635)$ & 0.000 \\
\hline Signet ring cell carcinoma & $32.5 \%$ & & & $0.601(0.408 \sim 0.885)$ & 0.010 \\
\hline yp T stage & & 148.323 & 0.000 & & 0.000 \\
\hline 1 & $88.6 \%$ & & & Ref & \\
\hline 2 & $87.9 \%$ & & & $0.293(0.212 \sim 0.405)$ & 0.000 \\
\hline 3 & $77.9 \%$ & & & $0.303(0.239 \sim 0.384)$ & 0.000 \\
\hline 4 & $62.6 \%$ & & & $0.584(0.494 \sim 0.692)$ & 0.000 \\
\hline LNs & & 2.234 & 0.135 & $\mathrm{NI}$ & \\
\hline$\leq 12$ & $78.5 \%$ & & & & \\
\hline$>12$ & $79.8 \%$ & & & & \\
\hline NLN & & 78.060 & 0.000 & & 0.000 \\
\hline$\leq 9$ & $74.3 \%$ & & & Ref & \\
\hline$>9$ & $82.8 \%$ & & & $1.623(1.457 \sim 1.809)$ & 0.000 \\
\hline
\end{tabular}



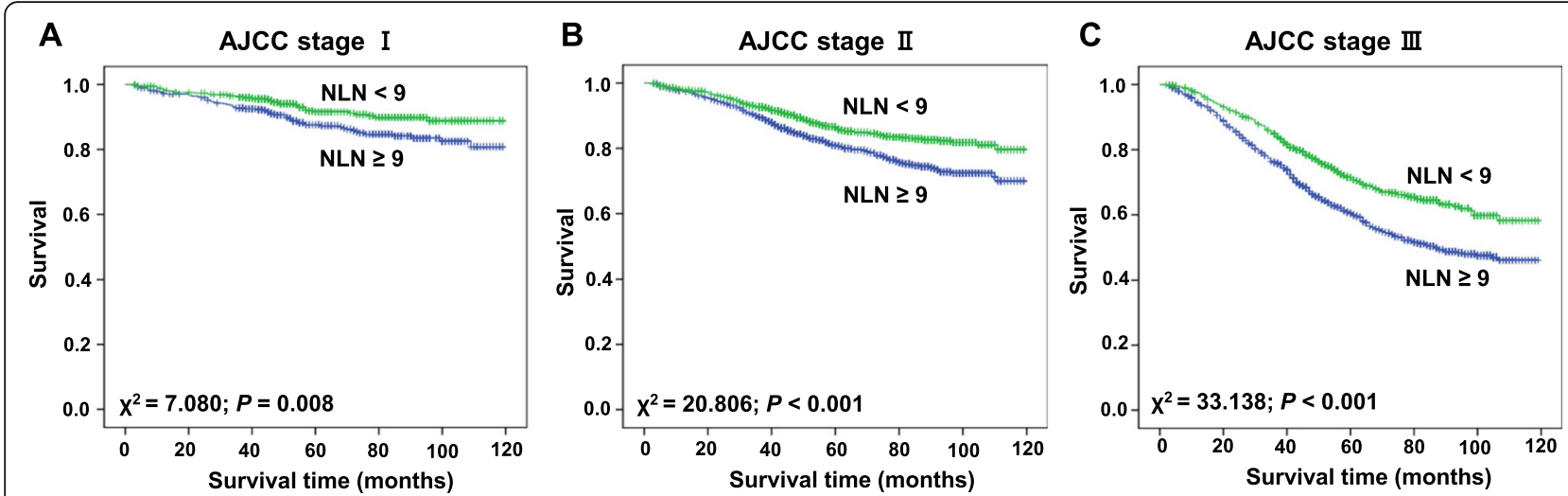

Fig. 2 Log-rank tests of CSS comparing patients with NLNs (<9 VS $\geq 9$ ) for (a) stage ypl: $P=0.008$; (b) stage ypll: $P<0.001$; and (c) stage yplll: $P<0.001$

Table 4 Univariate and multivariate survival analyses of stage ypl RC patients who received Pre-RT

\begin{tabular}{|c|c|c|c|c|c|}
\hline \multirow[t]{2}{*}{ Characteristic } & \multirow[t]{2}{*}{ 5-year CCS } & \multicolumn{2}{|c|}{ Univariate analysis } & \multicolumn{2}{|l|}{ Multivariate analysis } \\
\hline & & $x^{2}$ test & $P$ & $\mathrm{HR}(95 \% \mathrm{Cl})$ & $P$ \\
\hline Year of diagnosis & & 6.324 & 0.012 & & 0.035 \\
\hline 2004-2007 & $87.9 \%$ & & & Ref & \\
\hline 2008-2010 & $92.2 \%$ & & & $1.609(1.029 \sim 2.517)$ & 0.037 \\
\hline Sex & & 1.238 & 0.266 & $\mathrm{NI}$ & \\
\hline Male & $90.0 \%$ & & & & \\
\hline Female & $89.3 \%$ & & & & \\
\hline Age & & 2.359 & 0.125 & $\mathrm{Nl}$ & \\
\hline$<60$ & $91.3 \%$ & & & & \\
\hline$\geq 60$ & $88.0 \%$ & & & & \\
\hline Race & & 6.222 & 0.045 & & 0.053 \\
\hline White & $88.9 \%$ & & & Ref & \\
\hline Black & $81.0 \%$ & & & $3.792(1.201 \sim 11.968)$ & 0.023 \\
\hline Others & $98.9 \%$ & & & $4.392(1.251 \sim 15.415)$ & 0.021 \\
\hline Grade & & 0.483 & 0.487 & $\mathrm{Nl}$ & \\
\hline Grade I/ II & $90.0 \%$ & & & & \\
\hline Grade III/ IV & $85.1 \%$ & & & & \\
\hline Histologic type & & 3.218 & 0.200 & $\mathrm{NI}$ & \\
\hline Adenocarcinoma & $89.8 \%$ & & & & \\
\hline Mucinous adenocarcinoma & $89.5 \%$ & & & & \\
\hline Signet ring cell carcinoma & $50.0 \%$ & & & & \\
\hline ypT stage & & 0.001 & 0.972 & $\mathrm{Nl}$ & \\
\hline 1 & $90.5 \%$ & & & & \\
\hline 2 & $89.4 \%$ & & & & \\
\hline LNs & & 9.401 & 0.002 & & 0.284 \\
\hline$\leq 12$ & $87.8 \%$ & & & Ref & \\
\hline$>12$ & $93.4 \%$ & & & $1.702(0.949 \sim 3.052)$ & 0.074 \\
\hline NLN & & 7.080 & 0.008 & & 0.600 \\
\hline$\leq 9$ & $87.6 \%$ & & & Ref & \\
\hline$>9$ & $91.6 \%$ & & & $1.128(0.682 \sim 1.866)$ & 0.638 \\
\hline
\end{tabular}


NLN count ranging from 0 to 23. The 5-year CSS was calculated for patients with $\mathrm{N}$ (NLNs number) or more nodes and less than $\mathrm{N}$ nodes. As shown in Table 1, NLN count in patients with RC who received Pre-RT was a prognosis factor for number ranging from 0 to 23. With the NLN count increased from 0 to 23, the 5-year CSS rate increased from 51.8 to 88.8\% (Table 1). Next X-tile plots were constructed and the maximum $\mathrm{X}^{2}$ log-rank value of 78.060 (the number as 9, Fig. $1, P<0.001)$ was produced, applying 9 as the optimal cutoff value to divide the cohort into high and low risk subsets in terms of CSS. There was a significant improvement in 5 -year CSS between two subsets (74.3\% v.s. $82.8 \%$, Table 1$)$. As shown in Table 2, the year of diagnosis, sex, age and the average number of LNs dissected were significantly different between patients with NLN $\leq 9$ or $>9$ $(P<0.05)$.

\section{Impact of the NLN count on CSS in RC patients who received Pre-RT}

According to univariate analysis, age $(\geq 60)$, race (black persons), grade (III/IV), histologic type (signet ring cell carcinoma), ypT stage (ypT3 and ypT4) and NLNs $(\leq 9)$ were associated with poor outcomes in patients with RC who received Pre-RT $(P<0.001)$ (Table 3$)$. In multivariate Cox analysis, age, grade, histologic type, ypT stage and NLN counts were independently prognostic factors $(P<0.001$, Table 3$)$. NLN counts $(>9)$ exhibited

Table 5 Univariate and multivariate survival analyses of stage ypll RC patients who received Pre-RT

\begin{tabular}{|c|c|c|c|c|c|}
\hline \multirow[t]{2}{*}{ Characteristic } & \multirow[t]{2}{*}{ 5-year CCS } & \multicolumn{2}{|c|}{ Univariate analysis } & \multicolumn{2}{|l|}{ Multivariate analysis } \\
\hline & & $x^{2}$ test & $P$ & $\mathrm{HR}(95 \% \mathrm{Cl})$ & $P$ \\
\hline Year of diagnosis & & 0.255 & 0.614 & $\mathrm{Nl}$ & \\
\hline 2004-2007 & $84.1 \%$ & & & & \\
\hline $2008-2010$ & $84.7 \%$ & & & & \\
\hline Sex & & 1.414 & 0.234 & $\mathrm{Nl}$ & \\
\hline Male & $85.1 \%$ & & & & \\
\hline Female & $83.0 \%$ & & & & \\
\hline Age & & 21.435 & 0.000 & & 0.000 \\
\hline$<60$ & $87.2 \%$ & & & Ref & \\
\hline$\geq 60$ & $81.1 \%$ & & & $0.677(0.566 \sim 0.810)$ & 0.000 \\
\hline Race & & 1.812 & 0.404 & $\mathrm{Nl}$ & \\
\hline White & $84.6 \%$ & & & & \\
\hline Black & $81.4 \%$ & & & & \\
\hline Others & $84.4 \%$ & & & & \\
\hline Grade & & 24.552 & 0.000 & & 0.000 \\
\hline Grade I/ II & $85.6 \%$ & & & Ref & \\
\hline Grade III/ IV & $76.2 \%$ & & & $0.599(0.479 \sim 0.748)$ & 0.000 \\
\hline Histologic type & & 6.705 & 0.035 & & 0.042 \\
\hline Adenocarcinoma & $85.0 \%$ & & & Ref & \\
\hline Mucinous adenocarcinoma & $75.9 \%$ & & & $0.786(0.249 \sim 2.481)$ & 0.682 \\
\hline Signet ring cell carcinoma & $71.6 \%$ & & & $1.103(0.339 \sim 3.590)$ & 0.871 \\
\hline ypT stage & & 21.301 & 0.000 & & 0.000 \\
\hline 3 & $85.4 \%$ & & & Ref & \\
\hline 4 & $73.2 \%$ & & & $0.591(0.445 \sim 0.767)$ & 0.000 \\
\hline LNs & & 9.648 & 0.002 & & 0.892 \\
\hline$\leq 12$ & $82.5 \%$ & & & Ref & \\
\hline$>12$ & $86.7 \%$ & & & $0.983(0.749 \sim 1.289)$ & 0.900 \\
\hline NLN & & 20.806 & 0.000 & & 0.002 \\
\hline$\leq 9$ & $80.9 \%$ & & & Ref & \\
\hline$>9$ & $86.5 \%$ & & & $1.520(1.170 \sim 1.975)$ & 0.002 \\
\hline
\end{tabular}


a favorable effect on survival $(\mathrm{HR}=1.623,95 \% \mathrm{CI}$ $1.457 \sim 1.809, P<0.001$, Table 3 ).

\section{Impact of the NLN count on CSS in RC patients based on each pathological grade}

We then further analyzed of the effects of NLN on survival in each subgroup of stage yp I, yp II and yp III. As shown in Fig. 2, subgroup analysis showed that NLN was a prognosis factor for patients with $\mathrm{RC}$ who received PreRT in stage ypI ( $\chi 2=7.080 ; P=0.008)$, ypII $\left(\chi^{2}=20.806\right.$; $P<0.001)$ and ypIII ( $\mathrm{x} 2=33.138 ; P<0.001)$, respectively. Moreover, as shown in Tables 4, 5 and 6, the NLN count was also an independently prognostic factor in stage ypII
(HR: $1.520,95 \%$ CI: $1.170 \sim 1.975 ; P=0.002$ ) and ypIII (HR: $1.466,95 \%$ CI: $1.264 \sim 1.700 ; P<0.001$ ) after adjustment for potential confounders.

\section{Discussion}

LN metastasis is considered as one of the most significant prognostic factors in RC [11]. The total number of LNs retrieved is fundamental in most pathological staging systems for RC. Inadequate LN evaluation is associated with worse outcomes in terms of tumor recurrence and patient survival [12]. Thus, looking for effective means of assessment of LNs on survival can provide more accurate prognostic information.

Table 6 Univariate and multivariate survival analyses of stage yplll RC patients who received Pre-RT

\begin{tabular}{|c|c|c|c|c|c|}
\hline \multirow[t]{2}{*}{ Characteristic } & \multirow[t]{2}{*}{ 5-year CCS } & \multicolumn{2}{|c|}{ Univariate analysis } & \multicolumn{2}{|l|}{ Multivariate analysis } \\
\hline & & $x^{2}$ test & $P$ & $\mathrm{HR}(95 \% \mathrm{Cl})$ & $P$ \\
\hline Year of diagnosis & & 0.038 & 0.846 & $\mathrm{Nl}$ & \\
\hline 2004-2007 & $65.6 \%$ & & & & \\
\hline 2008-2010 & $67.0 \%$ & & & & \\
\hline Sex & & 0.026 & 0.872 & $\mathrm{Nl}$ & \\
\hline Male & $65.9 \%$ & & & & \\
\hline Female & $66.2 \%$ & & & & \\
\hline Age & & 17.245 & 0.000 & & 0.000 \\
\hline$<60$ & $69.3 \%$ & & & Ref & \\
\hline$\geq 60$ & $60.9 \%$ & & & $0.747(0.654 \sim 0.866)$ & 0.000 \\
\hline Race & & 17.535 & 0.000 & & 0.625 \\
\hline White & $66.8 \%$ & & & Ref & \\
\hline Black & $51.6 \%$ & & & $1.125(0.880 \sim 1.436)$ & 0.347 \\
\hline Others & $71.3 \%$ & & & $1.767(1.290 \sim 2.421)$ & 0.000 \\
\hline Grade & & 41.722 & 0.000 & & 0.000 \\
\hline Grade I/ II & $69.5 \%$ & & & Ref & \\
\hline Grade III/ IV & $53.9 \%$ & & & $0.670(0.566 \sim 0.794)$ & 0.000 \\
\hline Histologic type & & 24.617 & 0.000 & & 0.037 \\
\hline Adenocarcinoma & $67.4 \%$ & & & Ref & \\
\hline Mucinous adenocarcinoma & $60.7 \%$ & & & $0.562(0.378 \sim 0.836)$ & 0.004 \\
\hline Signet ring cell carcinoma & $41.8 \%$ & & & $0.588(0.383 \sim 0.904)$ & 0.016 \\
\hline урТ stage & & 66.241 & 0.000 & & 0.000 \\
\hline 1 & $73.0 \%$ & & & Ref & \\
\hline 2 & $83.7 \%$ & & & $0.442(0.242 \sim 0.810)$ & 0.008 \\
\hline 3 & $65.1 \%$ & & & $0.276(0.195 \sim 0.391)$ & 0.000 \\
\hline 4 & $46.8 \%$ & & & $0.564(0.451 \sim 0.704)$ & 0.000 \\
\hline LNs & & 1.975 & 0.160 & $\mathrm{NI}$ & \\
\hline$\leq 12$ & $64.9 \%$ & & & & \\
\hline$>12$ & $67.0 \%$ & & & & \\
\hline NLN & & 33.138 & 0.000 & & 0.000 \\
\hline$\leq 9$ & $60.5 \%$ & & & Ref & \\
\hline$>9$ & $71.4 \%$ & & & $1.466(1.264 \sim 1.700)$ & 0.000 \\
\hline
\end{tabular}


According to the AJCC-7 RC staging system, a 12node minimum is required for proper tumor stage and associated with a good survival outcome in patients treated with surgery [3]. Yet, the number of positive LN is often affected by many facts such as neoadjuvant therapy, and the number of LN retrieved and inspected [3]. Once the range of LN retrieved is not enough, the prediction of survival would be inaccurate. Therefore, the concept of NLN has been developed recently. NLN count has a unique advantage that it is little influenced by the number of LN retrieved [13]. The more NLN count is, the better the survival would be. Li et al. [12] reported that the optimal cutoff value of 10 was validated as an independent prognostic factor in stage ypIIIB and ypIIIC RC patients treated with Pre-RT. In this study, we found that the NLN count was an independent prognosis factor for all patients with $\mathrm{RC}$ who received Pre-RT. And we identified the optimal cutoff value for NLN count as 9. Obviously, NLN count is a good supplement for LN stage and TNM stage on evaluating the prognosis of patients with $\mathrm{RC}$ who received Pre-RT, respectively for patients with stage ypI, ypII and ypIII. Until now, there has been no report confirming the mechanism of NLNs influencing on the prognosis of $\mathrm{RC}$. But it is suggested that lymphatic micrometastasis is a key etiology of recurrence and metastasis after resection of RC [14]. LN micrometastasis, is common in nodes with the size ranging from 0.2 to $2.0 \mathrm{~mm}$ which determined to be negative by HE staining, but positive for cytokeratin (CK) by immunohistochemical staining [15]. Because it is difficult to find lymphatic micrometastasis during operation, we can retrieve more NLNs to reduce the residual micrometastases, in order to improve the prognosis of $\mathrm{RC}$.

The intended purpose of Pre-RT is tumor downstaging by decreasing the primary tumor bulk and reducing the burden of residual associated LN metastases at surgery, thus increasing the potential of margin-negative resections [9]. It has been reported that Pre-RT may cause radiation-induced lymphocyte destruction and stromal fibrosis resulting in alterations of the morphology of the LNs, making LN detection during operation more difficult [9]. Some researchers found that a decreased LN count after Pre-RT was related to good survival $[16,17]$. The NLN count is particularly useful in the prediction of survival because it is little influenced by the number of LN retrieved, and has potential to reflect the dissection of lymphatic micrometastasis. In this study, we revealed that NLN count was an independent prognostic factor for patients with $\mathrm{RC}$ who received Pre-RT. Subgroup analysis showed that NLN was a prognosis factor for patients with $\mathrm{RC}$ who received Pre-RT in stage ypI $(\chi 2=7.080 ; P=0.008)$, ypII $\left(\chi^{2}=20.806 ; P<0.001\right)$ and ypIII $\left(\chi^{2}=33.138\right.$;
$P<0.001)$, respectively. It might provide more accurate prognostic information than the $\mathrm{N}$ stage alone in patients with Pre-RT.

This study has several limitations. First, the SEER database does not include information of therapeutic options such as detailed information of chemotherapy, targeted therapy, immunotherapy, recurrence and metastasis, which may also impact patients' prognosis. Second, this data lack detailed description of preoperative clinical grading and the information about tumor and $\mathrm{LN}$ recession response to treatment, and our analyses could not adjust for these potential confounding factor. Third, different operative approaches, doctors and even pathologist would affect the detective rate of total LN and metastatic LN, but the SEER do not include these information [10]. Although future clinical research will be required to confirm the role of NLN, our study has its convincing power for it is one of the largest population based study until now.

\section{Conclusions}

Our results firmly demonstrated that NLN count was an independent prognostic factor for patients with $\mathrm{RC}$ who received Pre-RT. It could provide more accurate prognostic information for RC patients with Pre-RT (stage ypI, ypII and ypIII, respectively).

\section{Abbreviations \\ LN: Lymph node; NLN: Negative lymph node; Pre-RT: Preoperative radiotherapy; RC: Rectal cancer; SEER: Surveillance, Epidemiology, and End Results Program}

\section{Acknowledgements}

The authors acknowledged the efforts of the Surveillance, Epidemiology, and End Results (SEER) Program tumor registries in the creation of the SEER database. The interpretation and reporting of these data were the sole responsibility of the authors.

\section{Funding}

The design of the study and collection, analysis, and interpretation of data were supported by National Natural Science Foundation of China to Xinxing Li (Grant No. 81402002).

\section{Availability of data and materials}

The cohort data are available to researchers and should be requested under the approval of the SEER Program administration. The other datasets supporting the conclusions of this article are included within the article.

\section{Authors' contributions}

$\mathrm{ZQH}$ conceived and designed the study, XXL, HLW and XWL performed the analyses, KX, HLW and XWL provided assistance in writing the manuscript and support in interpreting results. All authors discussed the results and implications of the analysis and commented on the manuscript at all stages. All authors read and approved the final manuscript.

Competing interests

The authors declare that they have no competing interests.

Consent for publication

Not applicable. 


\section{Ethics approval and consent to participate}

Because the patients in the SEER database could not be identified, the analysis and reporting of the data in our study were exempt from review by the Ethics Board of Changzheng Hospital, the Second Military Medical University. The requirement for written informed consent to participate was waived. We were permitted to have Internet access after our signed data-use agreement (http://seer.cancer.gov/data/sample-dua.html) was approved by the SEER administration.

\section{Publisher's Note}

Springer Nature remains neutral with regard to jurisdictional claims in published maps and institutional affiliations.

\section{Received: 18 January 2017 Accepted: 22 March 2017}

Published online: 28 March 2017

\section{References}

1. Sung JJ, Ng SC, Chan FK, Chiu HM, Kim HS, Matsuda T, Ng SS, Lau JY, Zheng S, Adler S, et al. An updated Asia Pacific Consensus Recommendations on colorectal cancer screening. Gut. 2015;64(1):121-32.

2. van Gijn W, Marijnen CA, Nagtegaal ID, Kranenbarg EM, Putter H, Wiggers T, Rutten HJ, Pahlman L, Glimelius B, van de Velde CJ, et al. Preoperative radiotherapy combined with total mesorectal excision for resectable rectal cancer: 12-year follow-up of the multicentre, randomised controlled TME trial. Lancet Oncol. 2011;12(6):575-82.

3. Li Q, Zhuo C, Cai G, Li D, Liang L, Cai S. Increased number of negative lymph nodes is associated with improved cancer specific survival in pathological IIIB and IIIC rectal cancer treated with preoperative radiotherapy. Oncotarget. 2014;5(23):12459-71.

4. Damin DC, Rosito MA, Contu PC, Tarta C, Ferreira PR, Kliemann LM, Schwartsmann G. Lymph node retrieval after preoperative chemoradiotherapy for rectal cancer. J Gastrointest Surg. 2012;16(8): 1573-80.

5. He J, Wang H, Ma F, Feng F, Lin C, Qian H. Prognosis of lymph nodenegative breast cancer: Association with clinicopathological factors and tumor associated gene expression. Oncol Lett. 2014:8(4):1717-24.

6. Chen Y, Zhang L, Tian J, Ren X, Hao Q. Combining the negative lymph nodes count with the ratio of positive and removed lymph nodes can better predict the postoperative survival in cervical cancer patients. Cancer Cell Int. 2013;13(1):6

7. Hsu PK, Huang CS, Wang BY, Wu YC, Chou TY, Hsu WH. The prognostic value of the number of negative lymph nodes in esophageal cancer patients after transthoracic resection. Ann Thorac Surg. 2013;96(3):995-1001.

8. Johnson PM, Porter GA, Ricciardi R, Baxter NN. Increasing negative lymph node count is independently associated with improved long-term survival in stage IIIB and IIIC colon cancer. J Clin Oncol. 2006;24(22):3570-5.

9. Shridhar R, Dombi GW, Finkelstein SE, Meredith KL, Hoffe SE. Improved survival in patients with lymph node-positive gastric cancer who received preoperative radiation: an analysis of the Surveillance, Epidemiology, and End Results database. Cancer. 2011;117(17):3908-16.

10. Li Q, Liang L, Gan L, Cai G, Li X, Cai S. Effect of Lymph Node Count on Pathological Stage III Rectal Cancer with Preoperative Radiotherapy. Sci Rep. 2015:5:16990.

11. Baxter NN, Virnig DJ, Rothenberger DA, Morris AM, Jessurun J, Virnig BA. Lymph node evaluation in colorectal cancer patients: a population-based study. J Natl Cancer Inst. 2005;97(3):219-25.

12. Tepper JE, O'Connell MJ, Niedzwiecki D, Hollis D, Compton C, Benson 3rd AB, Cummings B, Gunderson L, Macdonald JS, Mayer RJ. Impact of number of nodes retrieved on outcome in patients with rectal cancer. J Clin Oncol. 2001;19(1):157-63.

13. Shi RL, Chen Q, Ding JB, Yang Z, Pan G, Jiang D, Liu W. Increased number of negative lymph nodes is associated with improved survival outcome in node positive gastric cancer following radical gastrectomy. Oncotarget. 2016:7(23):35084-91.

14. Zeng YJ, Zhang CD, Dai DQ. Impact of lymph node micrometastasis on gastric carcinoma prognosis: a meta-analysis. World J Gastroenterol. 2015; 21(5):1628-35.

15. Hayashi N, Ito I, Yanagisawa A, Kato Y, Nakamori S, Imaoka S, Watanabe H, Ogawa M, Nakamura Y. Genetic diagnosis of lymph-node metastasis in colorectal cancer. Lancet. 1995;345(8960):1257-9.
16. Fiorica F, Cartei F, Enea M, Licata A, Cabibbo G, Carau B, Liboni A Ursino S, Camma $C$. The impact of radiotherapy on survival in resectable gastric carcinoma: a meta-analysis of literature data. Cancer Treat Rev. 2007:33(8):729-40.

17. Skoropad V, Berdov B, Zagrebin V. Concentrated preoperative radiotherapy for resectable gastric cancer: 20-years follow-up of a randomized trial. J Surg Oncol. 2002;80(2):72-8.

\section{Submit your next manuscript to BioMed Central and we will help you at every step:}

- We accept pre-submission inquiries

- Our selector tool helps you to find the most relevant journal

- We provide round the clock customer support

- Convenient online submission

- Thorough peer review

- Inclusion in PubMed and all major indexing services

- Maximum visibility for your research

Submit your manuscript at www.biomedcentral.com/submit
Biomed Central 